\title{
Steroid Pulse Therapy in the Management of Neuropsychiatric Manifestations in an Atypical Presentation of Typhoid Fever
}

\author{
Ankur Jain, Gaurav Baheti
}

Department of Internal Medicine, Seven Hills Hospital, Mumbai, Maharashtra, India

Address for Correspondence: Ankur Jain, Department of Internal Medicine, Seven Hills Hospital, Mumbai, Maharashtra, India. E-mail: dr.ankurj@sevenhillshospital.com

\section{Abstract}

Typhoid fever presents often with a variety of clinical symptoms and numerous systemic complications. Neurological complications of enteric fever are relatively insidious and rare and many times late and often undiagnosed complication of typhoid fever, which can change the course of illness. This is a case of blood culture-proven typhoid fever with neuropsychiatric manifestations responded well with appropriate antibiotics and steroid pulse therapy ( $1 \mathrm{~g}$ methylprednisolone for 3 days).

\section{Keywords: Neuropsychiatric manifestations, Steroid, Typhoid}

\section{Introduction}

Typhoid fever is a systemic infection caused by Salmonella typhi. Typhoid fever may present with typical clinical presentation of continuous or intermittent fever associated with chills, anorexia, myalgia, headache, abdominal pain, and loose motion or constipation, ${ }^{[1]}$ whereas in some cases, these typical clinical features may not be present in all patients, and many times, typhoid fever may present in an atypical form, of which numerous complications more commonly like intestinal perforation. Apart from intestinal complication, neurological presentation constitutes a vivid and complex component of typhoid fever. ${ }^{[2]}$ "Typhoid" term derived from the Greek word "typos" which means smoke, and it was coined this term because of the neurological manifestation like delirium and confusion as a more common presentation of typhoid fever in pre-antibiotic era. ${ }^{[3]}$ The patients with high severity may develop "typhoid encephalopathy" with delirium, altered consciousness, confusion and other neurological symptoms such as an altered sleep pattern, myelitis, acute psychosis, meningitis, and focal neurological disorders which are extremely rare. ${ }^{[4]}$ Although various theories have explained the role of a possible toxin expressed by the bacteria or direct infection of the central nervous system or a possible autoimmune mechanism, the exact mechanism of the neuropsychiatric manifestations of typhoid fever still remains unclear. ${ }^{[5]}$

\section{Case Report}

A 26-year-old female with no prior comorbidities presented with intermittent high-grade fever of 7 days duration and few episodes of vomiting and watery diarrhea. On clinical examination, the vitals were stable. The general and physical examinations were also unremarkable.

His routine hematological and biochemical investigations were sent which was suggestive of leukopeniawithneutrophiliaand thrombocytopenia; serum electrolyte showed mild hyponatremia, whereas liver function test and renal function test were normal; malaria antigen and dengue antigen were negative and raised C-reactive protein level (7.15 mg/dl) and was started on intravenous (IV) antibiotics, third-generation cephalosporin, and metronidazole.

She developed neuropsychiatric manifestation on the $2^{\text {nd }}$ day of hospital stay in the form of hallucination, dissociative symptoms, irrelevant talk, and muttering with sleep disturbance. She was disoriented and confused, but there was no focal

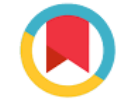

Check for updates

How to cite this article: Jain A, Baheti G. Steroid Pulse Therapy in the Management of Neuropsychiatric Manifestations in an Atypical Presentation of Typhoid Fever. Journal of Medical Research and Innovation. 2019;3(2):e000178.

DOI: 10.32892/jmri.178

Publication history: Received: 07-05-2019 Published: 01-07-2019

Editor: Dr. Varshil Mehta

Copyright: Jain A, Baheti G. This is an open access article distributed under the terms of the Creative Commons Attribution License CC-BY 4.0., which permits unrestricted use, distribution, and reproduction in any medium, provided the original author and source are credited.

Funding: NIL

Conflicts of Interest: NIL

MK Medkrux 
deficit; plantar reflex was bilateral flexor; there was no neck stiffness; and Kernig's sign was negative. His further blood workup showed increasing trend of CRP level, high procalcitonin level (3.32 ng/ml) and significant positive titer of the Widal test (Salmonella typhi $\mathrm{O}>1: 160$ and Salmonella typhi $\mathrm{H}>1: 640$ ) and positive typhi dot IgM immunoassay for Salmonella typhi. Magnetic resonance imaging of the brain with contrast study done, which was normal [Figure 1]. The cerebrospinal fluid study was unremarkable, and blood culture showed the growth of multidrugresistant Salmonella typhi.

IV antibiotics fluoroquinolones (levofloxacin) was added, and pulse steroids therapy (1 g methylprednisolone for 3 days) was administered. She gradually improved within 3 days and was discharged in stable condition with oral antibiotics.

- On follow-up after 1 week, the patient was better with no fever, abdominal pain, and irrelevant talk with completely normal examination.

\section{Discussion}

In the current case, our patient developed early neurological symptoms which is what, has been typically described by most of the authors with typhoid encephalopathy occur in the $3^{\text {rd }}$ week of illness in the form of "muttering delirium, ${ }^{[6]}$ and also, she is having neuropsychiatric manifestation in the form of hallucination and dissociative symptoms with sleep disturbance.

In a study of the neuropsychiatric manifestation of typhoid fever, Osuntokun et al. ${ }^{[6]}$ reported that majority of patients, i.e., $57 \%$ of cases have delirium, whereas a low proportion of patients has bilateral pyramidal signs (3\%) and transient extrapyramidal signs (1\%). Mononeuritis multiplex peripheral neuropathy and a few patients $(<1 \%)$ have late

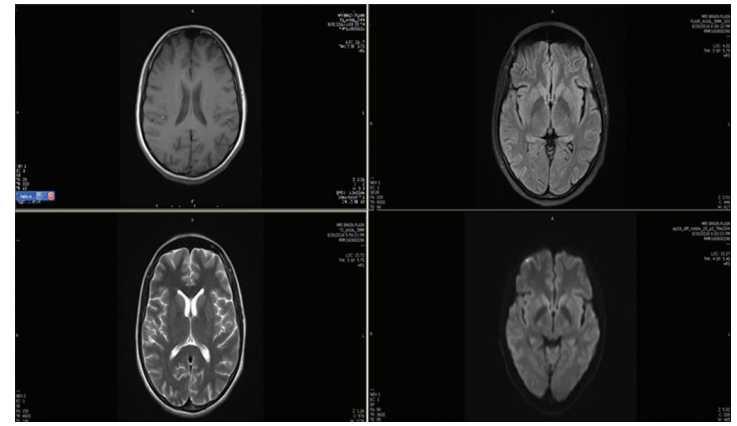

Figure 1: Magnetic resonance imaging of the brain showing no significant abnormality development of post-typhoidal psychosis. A study by Wadia et al., ${ }^{[7]}$ reported the presence of cerebellar ataxia (gait and limb ataxia) as one of the most common neurological manifestations of enteric fever, whereas nystagmus and speech disorders were the least common manifestations. However, in the present case, ataxia and other neurological symptoms were not present, and more of cognitive dysfunction was observed. We have administered pulse steroid therapy (1 g methylprednisolone for 3 days) for the treatment of typhoid encephalopathy in our case which gives better and rapid improvement as compared to other steroid therapies which were studied by other small studies which suggested that concurrent high doses of dexamethasone or hydrocortisone may have able to cause improvements in reducing the mortality and morbidity of the patients with typhoid encephalopathy. ${ }^{[4,8]}$ Moreover, it also has been suggested that a delay in the administration of steroids may lead to higher mortality or a relapse in typhoid encephalopathy. ${ }^{[9]}$

\section{Conclusion}

Typhoid fever presenting as neuropsychiatric manifestations is a neurological complication of this systemic illness. Hence, in patients presenting with high-grade fever and encephalopathy symptoms should not be designated febrile encephalopathy and should be evaluated for typhoid fever, especially in tropical countries such as India. Thus, prompt recognition of the typhoid encephalopathy before the availability of a bacterial culture report is very important for initiating an appropriate therapy (IV steroids, along with appropriate antibiotics).

\section{References}

1. Gorbach SL, Sleisenger MH, Fordtran JS. Infectious Diarrhea and Bacterial Food Poisoning. Gastrointestinal Disease. $5^{\text {th }}$ ed. Philadelphia: W.B. Saunders; 1993. p. 1128-73.

2. Le TP, Hoffman SL, Guerrant RL, Walker DH. Tropical Infectious Diseases. Principles, Pathogens and Practice. $2^{\text {nd }}$ ed. New York: Churchill Livingstone; 2006.

3. Osler W. The Principles and Practice of Medicine, Designed for the Use of Practitioners and Students of Medicine. NewYork: D Appleton; 1905.

4. Rogerson SJ, Spooner VJ, Smith TA, Richens J. Hydrocortisone in chloramphenicol-treated severe typhoid fever in Papua New Guinea. Trans R Soc Trop Med Hyg 1991;85:113-6.

5. Haque A. Neurological manifestations of enteric 


\section{Jain and Baheti: Steroid in Typhoid fever}

fever. In: Chopra JS, Sawhney IM, editors. Neurology in Tropics. $1^{\text {st }}$ ed. Vol. 506. New Delhi: BI Churchill Livingstone; 1999. p. 12.

6. Osuntokun BO, Bademosi O, Ogunremi K, Wright SG. Neuropsychiatric manifestations of typhoid fever in 959 patients. Arch Neurol 1972;27:7-13.

7. Wadia RS, Ichaporia NR, Kiwalkar RS, Amin RB, Sardesai HV. Cerebellar ataxia in enteric fever.
J Neurol Neurosurg Psychiatry 1985;48:695-7.

8. Hoffman SL, Punjabi NH, Kumala S, Moechtar MA, Pulungsih SP, Rivai AR, et al. Reduction of mortality in chloramphenicol-treated severe typhoid fever by high-dose dexamethasone. NEngl J Med 1984;310:82-8.

9. Cooles P. Adjuvant steroids and relapse of typhoid fever. J Trop Med Hyg 1986;89:229-31. 